\title{
A cost-analysis comparison of laparoscopic radical prostatectomy versus open radical prostatectomy: the McMaster Institute of Urology experience
}

\author{
Tariq F. Al-Shaiji, MB, ChB, FRCSC; ${ }^{*}$ Niki Kanaroglou, MD; ${ }^{*}$ Achilleas Thoma, MD, FRCSC; ${ }^{\dagger}$ Connie Prowse, \\ RN; ; Vikram Comondore, MD, ;illiam Orovan, MD, FRCSC; Kevin Piercey, MD, FRCSC,; Paul Whelan, MD, \\ FRCSC, ${ }^{*}$ Leo Winter, MD, FRCSC; Edward D. Matsumoto, MD, MEd, FRCSC ${ }^{*}$
}

See related article on page 242 .

\section{Abstract}

Introduction: The objective of this study was to identify and compare the costs of laparoscopic radical prostatectomy (LRP) and radical retropubic prostatectomy (RRP) at our centre.

Methods: We conducted a retrospective chart review of our first 70 consecutive LRP cases and 70 consecutive RRP cases at St. Joseph's Healthcare in Hamilton, Ontario, Canada. We performed cost analysis, including operating room costs, disposable instruments, blood transfusions, analgesic requirements and length of hospital stay. Overall expenses were then analyzed and compared. Results: Preoperative patient demographics and disease stages were comparable between the LRP and RRP groups. On a per procedure basis, large discrepancies were found in mean disposable instrument costs $(\mathrm{LRP}=\$ 659.18 \mathrm{vs}$. RRP $=\$ 236.59)$, operating room costs $(\mathrm{LRP}=\$ 4278.00$ vs. RRP $=\$ 3139.00)$, mean cost of blood transfusions $(\mathrm{LRP}=\$ 21.00 \mathrm{vs}$. RRP $=\$ 394.34)$, mean analgesia requirements $(\mathrm{LRP}=\$ 12.94 \mathrm{vs} . \mathrm{RRP}=\$ 41.06)$ and mean hospital stay bed costs $(\mathrm{LRP}=\$ 3690.00$ vs. RRP $=\$ 5027.14)$. Overall, costs for all patients in the LRP and RRP groups, respectively, were $\$ 606307.29$ and $\$ 618721.57$ with a cost saving of \$12 414.28 in favour of the LRP arm.

Conclusion: At our institution, we found that LRP costs are slightly less than those for RRP. Higher operative time and disposable instrument expenses are offset by the shorter hospital stays, fewer blood transfusions and less analgesic requirements for the LRP group. Further financial advantages for LRP will likely be achieved with additional reduction of operating room time and by minimizing disposables.

\section{Résumé}

Introduction : Le but de cette étude était de comparer les coûts $d^{\prime}$ 'une prostatectomie radicale par laparoscopie (PRL) et d'une prostatectomie radicale par voie rétropubienne (PRR) à notre centre.

Méthodologie : Nous avons procédé à un examen rétrospectif des dossiers des 70 premiers cas consécutifs de PRL et de 70 cas consécutifs de PRR au centre St. Joseph's Healthcare à Hamilton, en Ontario (Canada). Nous avons procédé à une analyse des coûts, y compris les coûts reliés à I'utilisation des salles d'opérations, au matériel jetable, aux transfusions sanguines, aux analgésiques requis et à la durée du séjour à I'hôpital. Les dépenses globales ont ensuite été analysées et comparées.
Résultats : Les deux groupes étaient comparables quant aux données démographiques et au stade de la maladie avant l'opération. Des différences importantes ont été décelées selon l'intervention dans les coûts moyens du matériel jetable (PRL $=659,18 \$$; PRR $=236,59 \$)$, les coûts liés à la salle d'opération ( $\mathrm{PRL}=4278,00 \$ ; \mathrm{PRR}=3139,00 \$$ ), le coût moyen des transfusions sanguines ( $P R L=21,00 \$$; $P R R=394,34 \$$ ), les exigences moyennes en matière $d^{\prime}$ 'analgésie $(P R L=12,94 \$$; PRR $=41,06 \$$ ) et les coûts moyens pour un lit pendant une hospitalisation $(\mathrm{PRL}=3690,00$; PRR $=5027,14$ \$). Globalement, les coûts pour l'ensemble des patients ayant subi une PRL ou une PRR étaient de 606 307,29 \$ et de 618 721,57 \$, respectivement; I'économie réalisée grâce à la PRL était donc de 12 414,28 \$.

Conclusion : À notre centre, nous avons observé que les coûts liés à la PRL étaient légèrement inférieurs à ceux d'une PRR. Des coûts plus élevés en lien avec le temps d'opération et le matériel jetable sont compensés par des séjours plus courts en hôpital et un nombre inférieur de transfusions sanguines et de doses d'analgésiques requises dans le groupe ayant subi une PRL. D'autres avantages financiers liés à la PRL découleront probablement d'une plus grande réduction du temps d'opération et de la quantité de matériel jetable utilisé.

Can Urol Assoc J 2010;4(4):237-41

\section{Introduction}

Prostate cancer is the most commonly diagnosed cancer in men worldwide. More than 22300 new cases of prostate cancer were diagnosed in Canada in 2007, and more than 4300 patients died of this disease. ${ }^{1}$ The cost per case and overall illness stages are estimated to be about \$35000 and the lifetime cost for these new cases is projected to exceed $\$ 8$ billion. ${ }^{2,3}$

Radical retropubic prostatectomy (RRP) is the standard surgical treatment for localized prostate cancer; however, attempts are being made to duplicate the outcomes of RRP with less invasive surgical techniques. ${ }^{4}$ Laparoscopic radical prostatectomy (LRP) was first described by Schuessler and then technically mastered by groups in France. ${ }^{5,6,7}$ Driven by patient desire for more minimally invasive approaches to prostatectomy, an increasing number of centres are now performing a large volume of LRPs.

The laparoscopic radical prostatectomy procedure presents many advantages. Patient-related benefits include 


\begin{tabular}{|c|c|c|c|c|c|c|c|c|}
\hline \multirow[b]{2}{*}{ Age } & \multicolumn{4}{|c|}{ RRP } & \multicolumn{4}{|c|}{ LRP } \\
\hline & $\begin{array}{c}\text { Mean } \\
62\end{array}$ & \multicolumn{2}{|c|}{$\begin{array}{c}\text { Range } \\
46-75\end{array}$} & $\begin{array}{c}S D \\
6.33\end{array}$ & $\begin{array}{c}\text { Mean } \\
60\end{array}$ & \multicolumn{2}{|c|}{$\begin{array}{c}\text { Range } \\
48-73\end{array}$} & $\begin{array}{c}S D \\
5.84\end{array}$ \\
\hline Clinical stage & $\begin{array}{l}\text { T1c } \\
41\end{array}$ & $\begin{array}{c}\text { T2a } \\
24\end{array}$ & $\begin{array}{c}\text { T2b } \\
3\end{array}$ & $\begin{array}{c}\text { T2c } \\
2\end{array}$ & $\begin{array}{c}\text { T1c } \\
55\end{array}$ & $\begin{array}{c}\text { T2a } \\
14\end{array}$ & $\begin{array}{c}\text { T2b } \\
1\end{array}$ & $\begin{array}{c}\text { T2c } \\
0\end{array}$ \\
\hline PSA & \multicolumn{2}{|c|}{56} & & & 67 & & & \\
\hline Gleason score & $\begin{array}{l}<7 \\
33\end{array}$ & & & $\begin{array}{l}>7 \\
7\end{array}$ & $\begin{array}{l}<7 \\
34\end{array}$ & & & $\begin{array}{c}>7 \\
4\end{array}$ \\
\hline
\end{tabular}

$\mathrm{RRP}=$ radical retropubic prostatectomy; $\mathrm{LRP}=$ laparoscopic radical prostatectomy; $\mathrm{SD}=$ standard deviation; $\mathrm{PSA}=$ prostate-specific antigen.

decreased length of stay, less analgesic requirement, fewer blood transfusions and faster overall recovery time resulting in less productivity loss. Technical advantages include improved surgical visualization, optical magnification, less tissue handling and less blood loss due to $\mathrm{CO}_{2}$ insufflation pressures. Many groups have also reported equivalent and occasionally better sexual and urinary function with LRP, when compared with RRP. ${ }^{8,9}$ Furthermore, early oncologic outcomes appear comparable. ${ }^{4,10,11}$ The disadvantages of LRP include a steep learning curve, decreased tactile feedback, lack of long-term outcome data, initially longer operative times and cost of disposables. ${ }^{8,9}$ There is an ongoing debate about the benefit of this procedure compared with its counterpart.

\section{Rationale}

Ultimately, oncologic efficacy, continence and potency are crucial in determining the value of LRP. However, a sensible financial profile is vital for its sustainability. Cost analysis of LRP has received surprisingly little attention in the literature, particularly in the setting of the Canadian health care system.

In one of the largest published LRP series addressing the subject of cost, Guillonneau and Vallancien found that LRP was actually cheaper than RRP at their institution in Paris, France. ${ }^{5}$ Savings were primarily due to shorter hospital stays. Using cost-analysis modelling, Lotan and colleagues found that LRP was almost as cost competitive as RRP. ${ }^{12}$ In a retrospective chart review 1 year later, the same group found that LRP costs were significantly greater than RRP ( $\$ 6760$ vs. \$5753). ${ }^{13}$ Their analysis showed that this difference stemmed from higher operating room and surgical supply costs of LRP. Link and colleagues developed a detailed computer model to predict perioperative costs of LRP and open RRP at Johns Hopkins Hospital, Baltimore, MD. They found that by minimizing disposable instruments and discharging LRP patients on postoperative day 2, LRP costs were equivalent to those of RRP. ${ }^{3}$ Overall, results seem positive, but are still widely variable at best. Ultimately, to remain a part of our surgical armamentarium, the LRP will need to be firmly proven to be economically viable.

\section{Objectives}

The primary objective of this study is to identify and compare the costs of LRP and RRP from an academic hospital's perspective. In doing so, we can identify potentially modifiable cost factors and, thereby, find ways to decrease overall costs for both procedures.

\section{Design and methodology}

\section{Population and data collection}

After obtaining approval from our local Research Ethics Board (St. Joseph's Hospital, Hamilton, Ontario), we performed a retrospective chart review of our first 70 consecutive LRP cases and the 70 consecutive RRP cases done during the same time interval (November 2004 to November 2005). Laparoscopic radical prostatectomy had just been introduced at our centre, and our goal was to capture cost differences at that point in time. Study patients included those diagnosed with organ-confined prostate cancer who underwent either RRP or LRP at St. Joseph's Healthcare in Hamilton. Procedures were performed by 5 attending urologists. Three performed RRP only, 1 performed LRP only, and 1 performed both. Using a data collection sheet that we constructed, the chart review was completed by 3 investigators for each patient. Data points are outlined in our results. Patient information was obtained from the hospital clinical browser, hospital patient charts and outpatient clinic charts.

\section{Cost calculation}

For this evaluation we used the hospital's perspective and calculated the costs which were relevant to the hospital alone. In doing so, we excluded other costs, such as productivity costs (indirect costs), which would have been relevant to patients and their families. We also excluded physician fees and home care costs, which would have been important to a third party payer which, in this case, would have been the Ministry of Health.

Variables in the analysis included costs from hourly operating room costs (based on operating room time and nurs- 
Table 2. Instrument costs

\begin{tabular}{|c|c|c|c|}
\hline Disposable items & $\begin{array}{c}\text { Cost per } \\
\text { item }\end{array}$ & $\begin{array}{l}\text { No. items used } \\
\text { (open) }\end{array}$ & $\begin{array}{l}\text { No. items used } \\
\text { (laparoscopic) }\end{array}$ \\
\hline Overhead table pack & 11.22 & 1 & 1 \\
\hline Lapo incise & 12.18 & 1 & - \\
\hline Chest breast drape & 7.78 & - & 1 \\
\hline Major prep & 7.54 & 1 & 1 \\
\hline Single basin & 5.98 & 1 & - \\
\hline Operating room kit prep kit major & 6.76 & 1 & 1 \\
\hline 16 French ( $5 \mathrm{cc} / 2$ way) Foley catheter & 6.30 & 1 & 1 \\
\hline 18 silicath (5 cc/2 way) & 14.58 & - & 1 \\
\hline \#22 Coleman catheter & 85.78 & 1 & - \\
\hline Urinemeter & 8.72 & 2 & 1 \\
\hline Foley catheter tray & 2.34 & 1 & 1 \\
\hline Suction tubing & 2.17 & 1 & 1 \\
\hline Suction liners & 1.15 & 1 & 1 \\
\hline *Elefant suction & 73.40 & - & 1 \\
\hline Drape tape & 0.79 & 1 & 1 \\
\hline Video camera drape & 3.20 & - & 1 \\
\hline Sterile water $1000 \mathrm{cc}$ (bottle) & 1.47 & - & 2 \\
\hline Normal saline 1000 cc (bottle) & 1.49 & 2 & - \\
\hline Normal saline 500 cc (bottle) & 1.35 & - & 1 \\
\hline Intravenous normal saline $1000 \mathrm{cc}$ & 2.08 & - & 2 \\
\hline Toomey syringe & 0.40 & 1 & 1 \\
\hline 20 cc syringe & 0.25 & 1 & 1 \\
\hline 10 cc syringe & 0.10 & 1 & 1 \\
\hline Bulb syringe & 1.55 & 1 & - \\
\hline Tuberculin syringe & 0.07 & - & 1 \\
\hline 10 cc control syringe & 0.79 & - & 1 \\
\hline \#22 needle & 0.05 & - & 1 \\
\hline Small tapes & 1.31 & 4 & 1 \\
\hline Medium tapes & 2.05 & 1 & - \\
\hline Raytex $(3 \times 3)$ & 0.35 & - & 1 \\
\hline Raytex (4×4) & 9.9 & 2 & - \\
\hline Lubricant $(5 / \mathrm{pkg})$ & 1.27 & 1 & 1 \\
\hline Medium large 'green' ligaclips & 3.54 & 4 & 8 \\
\hline Large 'orange' ligaclips & 5.11 & 2 & - \\
\hline Medium 'blue' ligaclips & 2.79 & 2 & - \\
\hline *10 mm optiview & 87.18 & - & 1 \\
\hline *10 mm sheath & 50.5 & - & 2 \\
\hline *5 mm trocar & 65.33 & - & 2 \\
\hline One seal reducer & 4.04 & - & 2 \\
\hline *10 mm endocatch & 120.33 & - & 1 \\
\hline Cautery pen vac & 4.51 & 1 & 1 \\
\hline Gowns (disposable X-L) & 3.76 & 4 & 4 \\
\hline \multicolumn{4}{|l|}{ Gloves } \\
\hline Brown & 3.45 & 1 & 1 \\
\hline White & 0.54 & 3 & 3 \\
\hline
\end{tabular}

Disposable laparoscopic instrument costs bolded. *Instruments accounted for the bulk of LRP cost (total: \$512.57). annual budgets. All costs are in Canadian dollars.

\section{Data analysis}

All parametric data were analyzed using a two-tailed T-test with an alpha of 0.05. All non-parametric data were analyzed using Mann-Whitney Rank Sum test, with an alpha of 0.05 .

\section{Results}

Preoperative demographics for patients in the 2 groups were comparable with respect to age, clinical stage, PSA and Gleason scores (Table 1). The RRP group had a slightly higher proportion of higher risk disease than the LRP group.

Using a micro-costing approach, we were able to capture the precise cost of each procedure. Instrument costs are based on our centre's contract pricing as outlined by our purchasing department. The disposable instrument cost for a single RRP was $\$ 236.59$ and $\$ 659.18$ for a single LRP. For the latter, 5 instruments accounted for the bulk of the cost (\$512.57) (Table 2). The cost of running the operating room includes overhead and administration costs, as well as nursing costs on an hourly basis (Table 3). As per our institution's budget, provided by our finance department, total hourly operating room costs (excluding equipment) is $\$ 1100$ per room. Mean operative time for RRP and LRP were 2.83 hours and 3.86 hours, respectively.

Mean overall costs of allogenic and autologous inpatient blood transfusions were calculated based on the Canadian Cost of Transfusion Study Group. Allogenic transfusions cost $\$ 210 /$ unit, versus autologous priced at $\$ 338 /$ unit. $^{14}$ At our institution, RRP patients are routinely given the option to store their own blood 2 weeks prior to the procedure. Mean operative blood loss in RRP and LRP patients was $849 \mathrm{~mL}$ and 241 $\mathrm{mL}$, respectively. The resulting costs from transfusions are substantially higher in the RRP group (Table 4).

Epidural analgesia, which is offered by ing/staff costs), disposable instruments, blood transfusions (autologous and allogenic), analgesia and hospital stay. All costs were based on standards in Ontario, Canada. Costs specific to our institution were determined by reviewing the anesthetist at our hospital, in the RRP group, accounted for most of the discrepancy in analgesic costs between the 2 groups (Table 5). All patients in the LRP received parenteral ketorolac tromethamine. The overall cost of analgesia 
Table 3. Comparison of operative costs

\begin{tabular}{lcc}
\hline & RRP $=\mathbf{7 0}$ & LRP $=$ 70 \\
\hline $\begin{array}{l}\text { Operating room time } \\
\text { (hours) }\end{array}$ & Mean: 2.83 & Mean: 3.86 \\
& Range: & Range: \\
& $1.80-5.50$ & $2.20-5.80$ \\
& SD: 0.64 & SD: 0.89 \\
\hline Total cost for operating & $\$ 219782.00$ & $\$ 299488.00$ \\
room & & \\
$\quad$ Mean cost per patient & $\$ 3139.00$ & $\$ 4278.00$ \\
\hline Total cost of disposable & $\$ 236.59 \times 70=$ & $\$ 659.19 \times 70=$ \\
instruments & $\$ 16561.30$ & $\$ 46143.30$ \\
$\quad$ Mean cost/patient & $\$ 236.00$ & $\$ 659.00$ \\
\hline
\end{tabular}

$\mathrm{RRP}$ = radical retropubic prostatectomy; LRP = laparoscopic radical prostatectomy;

$\mathrm{SD}=$ standard deviation

is relatively small, but RRP requirements were ultimately 3 times more costly.

Finally, as defined by the Ontario Health Insurance Plan (OHIP), the cost of a standard surgical bed is $\$ 900 / \mathrm{bed} /$ day. ${ }^{15}$ Mean length of stay was 5.6 days for the RRP group and 3.4 days for the LRP group. Bed costs are summarized in Table 6 .

Statistically significant differences in costs were found in the operating room, instruments, blood transfusion and analgesia (Table 7). The total cost savings for LRP compared with RRP, when all factors are considered, is \$12 414.28 for all 140 patients. On a per-procedure basis, this amount translates to a savings of $\$ 177.35$.

\section{Discussion}

Few studies have compared costs for RRP and LRP in the setting of Canadian health care. In the United States, Lotan and colleagues found that RRP was less costly than LRP primarily due to high equipment costs of the latter procedure. ${ }^{12}$ The savings from shorter hospital stays ( 1.3 vs. 2.5 days) were offset by the cost of longer operative times (200 vs. 160 minutes). In their computer model, Link and colleagues confirmed that cost equivalence could be achieved with LRP operative times of 204 minutes, the discharge of patients on postoperative day 2 , and the elimination of disposable scissors and trocars. ${ }^{3}$

When comparing minimally invasive treatments for prostate cancer to conventional RRP, Mouraviev and colleagues found that LRP costs were comparable to those of RRP (\$10 047 vs. \$10 704). ${ }^{16}$ While surgical costs for LRP

\begin{tabular}{lcc}
\hline \multicolumn{3}{l}{ Table 5. Comparison of analgesic costs } \\
\hline & $\mathbf{R R P}=\mathbf{7 0}$ & LRP $=\mathbf{7 0}$ \\
\hline Epidural analgesia & 39 & 0 \\
\hline Analgesia total & $\$ 2,874.27$ & $\$ 905.99$ \\
\hline Mean cost/patient & $\$ 41.06$ & $\$ 12.94$ \\
\hline $\begin{array}{l}\text { RRP }=\text { radical retropubic prostatectomy; } \mathrm{LRP}=\text { laparoscopic radical prostatectomy; } \\
\mathrm{SD}=\text { standard deviation. }\end{array}$ & & \\
\hline
\end{tabular}

\begin{tabular}{lcc}
\hline \multicolumn{3}{l}{ Table 4. Blood transfusions and associated costs } \\
\hline & RRP $=\mathbf{7 0}$ & LRP $=\mathbf{7 0}$ \\
\hline Estimated blood loss & Mean: 849.6 & Mean: 241.4 \\
& Range: $100-3500$ & Range: $50-1200$ \\
& SD: 646.7 & SD: 167.0 \\
\hline Number transfused & $42 / 70$ & $3 / 70$ \\
& Allogenic: 11 & Allogenic: 3 \\
Blood transfusions total & Autologus: 38 & Autologus: 0 \\
\hline Mean cost/patient & $\$ 27604.00$ & $\$ 1470.00$ \\
\hline RRP $=$ radical retropubic prostatectomy; LRP = laparoscopic radical prostatectomy; \\
SD = standard deviation.
\end{tabular}

were higher than RRP, all other costs were lower, including expenses for nursing care, pharmacy, respiratory care, cardiac service, radiology, laboratory and blood transfusions.

In France, Guilloneau and Vallencien found that the overall cost of RRP was about $\$ 1237$ more than that for LRP. ${ }^{17}$ Length of stay was the main factor accounting for this difference ( 6 days for LRP vs. 8.1 days for RRP). In particular, this study highlights the striking difference in accepted hospital stays in their centre as compared with ours. While this study still favours LRP, it underlines the importance of re-examining costs in the context of Canadian hospitals.

Although not statistically significant, our experience suggests that LRP is less costly overall than RRP. When considering the magnitude of overall expenses, the calculated difference is still small. The bulk of expenses for LRP lie in operating room costs and disposable equipment. These added expenses are almost completely counterbalanced by decreased length of stay, fewer blood transfusions and decreased analgesic requirements.

We acknowledge that RRP results can vary greatly between centres. Clinical pathways are now commonplace, which often accelerate discharge home. Furthermore, procedure times are often shorter in non-academic centres, where surgeons operate without trainees. Certainly these factors would affect overall costs of the RRP. We also note, however, that the reported LRP cases were our first 70 at McMaster University, and reflect longer operative times than our current standard. An updated analysis of more recent cases would not only reveal shorter operative times, but also less blood loss due to more surgeon experience and

Table 6. Costs of hospital stay

\begin{tabular}{lcc}
\hline RRP $=70$ & LRP $=70$ \\
\hline Length of stay (days) & Mean: 5.6 & Mean: 3.4 \\
& Range: $2-10$ & Range: $2-12$ \\
SD: 1.49 & SD: 1.84 \\
\hline $\begin{array}{l}\text { Hospital stay total } \\
\text { (\$900/day) }\end{array}$ & $\$ 351900.00$ & $\$ 258300.00$ \\
\hline Mean cost/patient & $\$ 5027.14$ & $\$ 3690.00$ \\
\hline $\begin{array}{l}\text { RRP }=\text { radical retropubic prostatectomy; } \text { LRP }=\text { laparoscopic radical prostatectomy; } \\
\text { SD = standard deviation. }\end{array}$ &
\end{tabular}




\begin{tabular}{|c|c|c|c|c|}
\hline & RRP & LRP & Cost saving (LRP) & $p$ Value \\
\hline Total cases $(n=140)$ & 70 & 70 & & \\
\hline Cost of operating room & $\$ 219782.00$ & $\$ 299488.00$ & $\$-79706.00$ & $<0.0001$ \\
\hline Cost of disposable instruments & $\$ 16561.30$ & $\$ 46143.30$ & $\$-29582.00$ & $<0.05$ \\
\hline Blood transfusions total & $\$ 27604.00$ & $\$ 1470.00$ & $\$ 26134.00$ & $<0.05$ \\
\hline Hospital stay total (\$900/day) & $\$ 351900.00$ & $\$ 258300.00$ & $\$ 93600.00$ & 0.1336 \\
\hline Analgesia total & $\$ 2874.27$ & $\$ 905.99$ & $\$ 1968.28$ & $<0.05$ \\
\hline Overall total & $\$ 618721.57$ & $\$ 606307.29$ & $\$-12414.28$ & 0.9798 \\
\hline
\end{tabular}

$\mathrm{RRP}=$ radical retropubic prostatectomy; $\mathrm{LRP}$ = laparoscopic radical prostatectomy.

comfort with this technically demanding procedure. Also, the average length of stay for standard LRP patients has since decreased by at least 24 hours, which would further diminish costs in a subsequent analysis.

This study dealt with the comparative costs of LPP and RRP from a university hospital's perspective. Further analysis could consider the Ministry of Health's perspective, in which investigators need to add not only the hospital costs but also surgical and anesthetic fees, as well as home care costs or any downstream costs (i.e., radiotherapy or chemotherapy if the need for these adjunctive treatments varies between the 2 procedures). One can go a step further and consider the societal perspective, in which the productivity costs (indirect costs) associated with these 2 competing interventions are also included.

The definitive "truth" can only be obtained from a parallel randomized controlled trial to which a methodologically sound economic evaluation is "piggy-backed." Such a trial should consider the perspective of the patient, the Ministry of Health (or other third party payer) and, finally, the society. ${ }^{18}$

\section{Conclusion}

This series shows that LRP is an economically viable option to RRP at our centre. We identified longer operating time and the use of disposable laparoscopic equipment as major contributors to the high cost of LRP. Both of these factors, particularly the latter, are at least partially modifiable. We identified transfusion, longer lengths of stay and epidural analgesia as contributing costs for RRP.

Future analysis will compare both functional and oncologic outcomes of these 2 approaches at our centre to help further define the role for each procedure in Canada. Furthermore, the robotic prostatectomy has gained widespread popularity in the United States, and is being used at select centres in Canada. A similar Canadian cost analysis, including all 3 modalities, should also be undertaken.

*Division of Urology, McMaster University, Hamilton, ON; †Division of Plastic Surgery, McMaster University, Hamilton, ON
Competing interests: None declared.

This paper has been peer-reviewed.

\section{References}

1. Canadian Cancer Statistics 2007. Toronto, ON: Canadian Cancer Society/National Cancer Institute of Canada; 2007.

2. Ruchlin HS, Pellissier JM. An economic overview of prostate carcinoma. Cancer 2001;92:2796-810.

3. Link RE, Su LM, Bayani SB, et al. Making ends meet: A cost comparison of laparoscopic and open radical retropubic prostatectomy. J Urol 2004; 172:269-74.

4. Menon M, Tewari A, Baize B, et al. Prospective comparison of radical retropubic prostatectomy and robotassisted anatomic prostatectomy: the Vattikuti Urology Institue experience. Urology 2002;60:864-8.

5. Guillonneau B, Vallencien G. Laparoscopic radical prostetectomy: the Montsouris technique. J Urol 2000;163:1643-9.

6. Guillonneau B, Vallencien $G$. Laparoscopic radical prostatectomy: initial experience and preliminary assessment after 65 operations. Prostate 1999;39:71-5.

7. Schuessler WW, Schulam PG, Clayman RV, et al. Laparoscopic radical prostatectomy: initial short-term experience. Urology 1997;50:854-7.

8. Omar AM, Townell N. Laparoscopic radical prostatectomy a review of the literature and comparison with open techniques. Prostate Cancer Prostatic Dis 2004;7:295-301.

9. Anastasiadis AG, Salomon L, Katz R, et al. Radical retropubic versus laparoscopic prostatectomy: a prospective comparison of functional outcome. Urology 2003;62:292-7.

10. Poulakis $V$, Dillenburg $W$, Moeckel $M$, et al. Laparoscopic prostatectomy: prospective evaluation of the learning curve. European Urology 2005;47:167-75.

11. Tse E, Knaus R. Laparoscopic radical prostatectomy - results of 200 consecutive cases in a Canadian Medical institution. Can J Urol 2004;11:2172-85.

12. Lotan Y, Cadeddu A, Gettman M. The new economics of radical prostatectomy: cost comparison of open, laparoscopic and robot assisted techniques. J Urol 2004;172:1431-5.

13. Anderson JK, Murdock A, Cadeddu JA, et al. Cost comparison of laparoscopic versus radical retropubic prostatectomy. Urology 2005;66:557-60.

14. Tretiak R, Laupacis A, Riviere $M$, et al. Cost of allogenic and autologous blood transfusion in Canada. Canadian Cost of Transfusion Study Group. CMAJ 1996;154:1501-8.

15. St Josephs Healthcare, Patient Accounts, 2006. Preferred Accommodation Form [invoice]. October 2006. Hamilton, ON: St Joseph's Healthcare.

16. Mouraviev V, Nosnik I, Sun L, et al. Financial comparative analysis of minimally invasive surgery to open surgery for localized prostate cancer: a single-institution experience. Urology 2007;69:311-4.

17. Guillonneau B, Vallencien G. Laparoscopic radical prostetectomy: the Montsouris experience. J Urol 2000;163:418-22

18. Thoma A, Strumas N, Rockwell G, et al. The Use of Cost-Effectiveness Analysis in Plastic Surgery Clinical Research. Clin Plast Surg 2008;35:285-96.

Correspondence: Dr. Edward D. Matsumoto, Assistant Professor, McMaster University, Department of Urology, St. Joseph's Hospital, 50 Charlton Ave. East, Hamilton, ON, L8N 4A6; fax: 905-3087205; matsumo@mcmaster.ca 